\title{
Analysis on the Usability of Spatial Layout of Urban Medical and Health Facilities
}

\author{
Shandey Pruti \\ Govind Ballabh Pant Social Science Research Institute, Jhusi, Pryagraaj, India \\ shandeypruti88@gmail.com
}

\begin{abstract}
The spatial organization of the HCFs denotes the way services are organized on a particular geographical unit. In the spatial organization the focus is not only on the points of study on a horizontal surface. It also encompasses the hierarchical level of provision of HCFs both in a geographical and administrative area. With this in the study of spatial organization the distance between the two points of the study was also covered. The spatial patterning of availability however studies the distribution of HCFs vis - à - vis spatial distribution of population. In this context the paper explains the structure of HCFs in the country in general and particularly the state of Uttar Pradesh from the point of hierarchy of provision of various level of health care facilities and their administrative structure It also attempts to indicate the possible implication of the existing patterns in terms of their availability, accessibility and utilization.
\end{abstract}

Keywords: availability, accessibility, utilization, location, Organization

\section{Introduction}

The health care infrastructure in India is consisted at three hierarchical levels. The first one is primary health care, second one is secondary and third one is at tertiary level. At all the three hierarchical levels services are provided by both public as well as private health care system. Role of public health care system in providing health care facilities to rural areas become important due to its norm to provide both preventive as well as curative type of services. In private healthcare system no doubt curative services are better than public health care system but their role is minimized when we see their contribution in promotion of preventive cure. In India Role of state in provision of health care facilities is important because health is a state subject in our constitution. State has the prime responsibility in providing the health care services to its citizens as per the constitution of India. In this regard delivery of public health care services has been operating in India from national to the state and district level and even in the village level. Health administration is considered as an essential element of proper delivery of health care services. It is the administration that organizes, manages and regulates the health services which is curative, promotive and preventive to become reachable to the masses. Accordingly at national level the administration of health services are such that there is a department of health, a ministry of health and a technical wing to support the health department. There is Union Ministry of Health and Family Welfare consisting of three departments, viz. Health, Family Welfare, and Indian System of Medicine and Homeopathy, headed by two Secretaries, one for Health and Family Welfare and the other for Indian System of Medicine and Homeopathy. The Directorate General of Health Services headed by Director General of Health Services (DGHS) supports the department of health. Similarly in the state level there exist a State Department of Health and Family Welfare which is headed by Minister and a Secretariat. Like central level there is also State Directorate of Health Services which is acting as a technical wing to support the State Department of Health and Family Welfare. However, the organizational structure of health is not uniform in all the states throughout the country.

In Uttar Pradesh for the delivery of health care services to the people, public health care has been organized at three levels - central level, intermediate level and primary level. Regional hospitals, medical college hospitals and specialized hospitals mainly constitute the central level institutions for delivery of health care, and these are usually located in the urban areas. Here the health care consists not only highly specials care, but sustain primary health care as a part of comprehensive national health system. At the secondary level there exists sub divisional and district hospitals and provides support to the primary health care institutions. The third level that is the primary level is very much concerned with the rural areas. The delivery of health care in the rural areas constitutes the primary level. The primary level is the point of contact between individuals and the health system. The primary level of the health care system is also called as rural health care system.

\subsection{Structure of Public Health Care Facilities in Rural Areas}

The available rural health care delivery system of India comes in three major types. One is the public health system, and the others are the private health system, and the network of traditional healers. These three come together to form the rural health - care delivery system of the country. However the public health care system is the prime source of health delivery system in the country.

The government of India has established the public health system throughout the country to reach each and every poor and unprivileged class and the areas with the basic health facilities. The network of public health centres is found extensively spread over the rural areas in the form of three tier system of a) sub - centre (SC), b) primary health centre (PHC) and c) community health centre (CHC). These health centres are established with the aim of providing primary health care available to and accessible for the rural masses. The structure and the available facilities in SC, PHC and $\mathrm{CHC}$ are: 


\section{a) Sub - Centre}

Sub - Centre lies at the bottom of the pyramid of health care system in the rural areas. It is the first contact point of the community for primary health care. The standard norms of sub - centres are for each 5000 population in the plain areas and in the hilly/tribal/difficult areas the population norms for each sub centre is 3000 . The sub - centers have to perform the tasks relating to interpersonal communication in order to bring about behavioral change in the health practices. It provide services in to maternal and child health, family welfare, nutrition, immunization, diarrhea control and control of communicable diseases. The sub centres are provided with some basic infrastructure of man power or health attendants and some essential drugs for minor ailments and for the need of taking care of immediate health needs of men, women and children. In each sub - centre there is one auxiliary nurse midwife (ANM) and one multipurpose worker (MPW), one lady health visitor (LHV) is entrusted with the task of supervision of six Sub - Centers.

\section{b) Primary Health Centre}

The PHC is the first contact point between village community and the Medical Officer. These were envisaged to provide an integrated curative and preventive health care to the rural Population with emphasis on preventive and promotive aspects of health care. The population norm for each PHC in plain areas is 30,000 and for the hilly, tribal or difficult area is 20,000. The PHCs are established and maintained by the State Governments. At present, a PHC is manned by a Medical Officer supported by 14 paramedical and other staffs. It acts as a referral unit for 6 Sub Centres. It has 4 - 6 beds for patients. The activities of PHC involve curative, preventive, primitive and family welfare services. Many rural dispensaries have been upgraded to create these PHCs. There exists fifteen numbers of staffs in primary health centre who are one medical officer, one pharmacist, one nurse, one health worker (female) or auxiliary nurse midwife (ANM), one health educator, one health assistant (male), one health assistant (female) or lady health visitor (LHV), one upper division clerk, one lower division clerk, one laboratory technician, one driver (subject to availability of vehicle) and four class IV grade clerk.

\section{c) Community Health Centre:}

The CHCs are being established and maintained by the State Government under Minimum Needs Programme. The population norm for each community centre in plain areas is 1, 20, 000 and for the hilly, tribal or difficult area is 80,000 . It is manned by four medical specialists i. e. surgeon, physician, gynecologist and pediatrician supported by 21 paramedical and other staff. It has 30 in - door beds with one operation theatre, xray, labour room and laboratory facilities. It serves as a referral for 4 PHCs and also provides facilities for obstetric care and specialist consultations. Though these public health centers are to provide health facilities to the rural masses but it is found that these health centres are suffering from weak infrastructure, scanty fund, under staffed etc. All these make delivery of health services poor and thereby reduce the demand for public health facilities.

\section{d) Traditional Healthcare:}

Existence of traditional healers and their health services is another significant health care practices prevailing in rural areas of India. In the system of rural health care delivery traditional practices have a great importance. There are different types of traditional health practices. Homeopathy, Ayurvedic care, Unani, Siddha, and Bopha are just a few 77 types of these traditional medicine practices and are very much alive in many parts of our country. These traditional healers however, are the most preferable source of medical relief in the rural areas. The rural populations have a great belief in this traditional practice and thus still these practices are prevailing amongst them. Some of the traditional practices have become a culture of rural Indian society. Ayurveda commonly defined as the 'knowledge of life' is the most traditional medical system of India and has been practiced widely throughout the country from time immemorial. Such of these practices have become an inseparable part of life. The traditional medicine has focused on maintaining health through healthy living. It is to be mentioned that by working with these healers, and teaching them how to diagnose and treat the more common illnesses in rural India, some doctors and NGO's are successful in creating new pathways to treatment. However, as India continues to globalize, rural populations are having to battle with unsafe drinking water, polluted air, lack of nutritious food, leading to the breakdown of traditional communities.

As the time passed these practices are losing their importance and are confined to only few both in terms of demand for and supply of these health care. These traditional healers being an important part of the medical system in India cannot be treated as backdated as the country moves forward, and thus, the government of India has given priority in development of these practices in its different plans. In the First Five Year Plan the need of development of the indigenous systems of medicine was felt and importance was given on research into all its aspects. Urgency was felt to clear the existence of great uncertainty prevailing about the position and the future course of development of indigenous systems, homeopathy and nature care. From Seventh plan onwards a significant emphasis was given on popularization and development of Indian System of medicine. During the period of Eight Five Year Plan, the Department of Indian Medicine and Homeopathy was created which on 2003 renamed as the Department of Ayurveda, Yoga and Naturopathy, Unani, Siddha and Homeopathy (AYUSH). The department was established with the main objectives of up gradation of AYUSH educational standards, quality control and standardization of drugs, improving the availability of medicinal plant material, research and development and awareness generation about the efficacy of the systems domestically and internationally. In the mid of Tenth Five Year Plan, under NRHM, mainstreaming AYUSH with public health care system is remarkable. The mission took the steps to revitalize local health traditions, developed AYUSH infrastructure, manpower, make AYUSH medications available in the village level public health centres, etc. All these led to the development of the indigenous traditional health practices and also strengthened the delivery of public health care services.

The healthcare system in rural India runs as a three - tier system based on the following population norms: in plain areas, every sub - centre covers a population of 5000 and in 
hilly or tribal areas it covers only a population of 3000 . Likewise, the primary health centers and community health centers also covered a definite proportion of the population. A primary health center covers 30,000 populations in plain areas against the 20,000 of the population in hilly or tribal areas. According to the area, community health centers (CHC's) also have a different population norm. In plain areas, a CHC covers a population of 1,20, 000 while in hilly areas this proportion of the population is limited only to 80 , 000 .

Table 1: Population norms for Health Infrastructure in Rural India (Public Sector)

\begin{tabular}{|c|c|c|}
\hline \multirow{2}{*}{ Centre } & \multicolumn{2}{|c|}{ Population Norms } \\
\cline { 2 - 3 } & Plain areas & Hilly /Tribal Areas \\
\hline Sub centre (SC) & 5000 & 3000 \\
\hline Primary Health Centre (PHC) & 30000 & 20000 \\
\hline Community Health Centre (CHC) & 1,20000 & 80000 \\
\hline
\end{tabular}

Source: Health and Family Welfare Statistics in India, 2013.

Apart from the above discussed hierarchy in the provision of rural HCFs, there also exist rural hospitals and dispensaries. The rural dispensaries are of two types: (i) of indigenous system of medicine, and (ii) of modern allopathic medicine. Many of these have been upgraded as PHCs after the implementation of National Health Policy, 1983. The rural dispensaries are manned by one doctor and one or two multi - purpose workers. Sometimes there was only medicine distributor who acts as a subordinate of doctor and gives medicine to the villagers.

Table 2: Numbers of SCs, PHCs, and CHCs Functioning in India from 2001 to 2015

\begin{tabular}{|c|c|c|c|}
\hline Year & SCs & PHCs & CHCs \\
\hline 2001 & 137311 & 22842 & 3043 \\
\hline 2004 & 142655 & 23109 & 3222 \\
\hline 2005 & 146026 & 23236 & 3346 \\
\hline 2007 & 145272 & 23370 & 4045 \\
\hline 2010 & 147069 & 23673 & 4535 \\
\hline 2011 & 148124 & 23887 & 4809 \\
\hline 2012 & 148366 & 24049 & 4833 \\
\hline 2013 & 151684 & 24448 & 5187 \\
\hline 2014 & 152326 & 25020 & 5363 \\
\hline 2015 & 153655 & 25308 & 5396 \\
\hline
\end{tabular}

Source: National Health Profiles, Ministry of Health and Family Welfare, Government of India.

Table. 2 presented the Healthcare infrastructure over the years from 2001 to 2015 . Over the period there were a sustained increment in the number of SCs, PHCs and CHCs.

\subsection{Health Manpower in Primary Healthcare in India}

Health manpower is defined as the people who are specialized in promoting health, in preventing and curing diseases. Therefore, the primary objective of health workforce is to provide specialized health personnel in the desired number with all the suitable skills at the right time or right place. The performance of healthcare system of any country depends on the availability of the health care infrastructure and health manpower. Though India has shown progress in the healthcare sector, still there are many areas in the country where there is hardly any physician, Midwife/ ANM available in case of any emergency. It is one of the most crucial aspects of the healthcare system. The situation in the availability of specialist health manpower in India's health sector is even more alarming. Although the number of specialists in broad terms specialists of internal medicine, general surgery etc. being inadequate, is within manageable proportion, but the availability of specialists in emerging internal diseases is much less. In the country, there is an imbalance in the rural - urban availability of specialized doctors, with more advanced and specialist physicians and doctors being available in the urban areas of the country. The reason, why in rural or remote areas the mortality rates are high comparatively to the urban and plain areas, is that people have to go a long distance for seeking healthcare.

India is lagging far behind in all the three indicators of health system. According to the MCI (Medical Council of India), the total number of registered doctors is 9, 36, 488 in 2014. As per the norms of World Health Organization (WHO), there must be 25 health workers per 10, 000 populations, while India has only 19 health worker (doctors, nurses, and midwives) per 10, 000 populations. The number of Auxiliary Nurse Midwives (ANM) are 7, 56, 937 in 2013 in the country. However, when we compared India with the number of the Indian population of more than 1.21 billion, it shows a doctor - population ratio of 1: 1700 people against the WHO minimum norm of one doctor for every thousands of population, which is below to that of developed countries and some developing countries. The table shows the availability of health workforce in an international perspective. Table.2; itself narrate the whole story of India's health manpower availability status. Against the developed and some developing countries, India has just 17.1 Nursing and Midwifery health personnel per 10, 000 population against the 51.1 nurses and Midwifery personnel for South Africa in 2015. India has only 7.0 physicians per 10.000 population in 2015 which is much fewer than the developed countries such as Canada which has (20.7), France (31.9), Switzerland (40.5), United Kingdom (28.1), and United State of America (24.5). Among the developing countries, Brazil has the highest number of physicians per 10, 000 populations. Brazil has 18.9 physicians in 2015 against 14.9 physicians in China and 8.3 physicians in Pakistan respectively.

Table 3: Densities of Health Care personnel in international Perspective:

\begin{tabular}{|c|c|c|c|}
\hline Country & $\begin{array}{c}\text { Physicians } \\
\text { per } 1000\end{array}$ & $\begin{array}{c}\text { Nurse and } \\
\text { Midwife per 1000 }\end{array}$ & $\begin{array}{c}\text { Hospital Beds } \\
\text { per 100, 000 }\end{array}$ \\
\hline Bangladesh & 3.6 & 2.2 & 6 \\
\hline Brazil & 18.9 & 76 & 23 \\
\hline China & 14.9 & 16.6 & 38 \\
\hline Pakistan & 8.3 & 5.7 & 6 \\
\hline Indonesia & 2 & 13.8 & 9 \\
\hline Sri Lanka & 6.8 & 16.4 & 36 \\
\hline South Africa & 7.8 & 51.1 & 0 \\
\hline India & $\mathbf{7}$ & $\mathbf{1 7 . 1}$ & $\mathbf{7}$ \\
\hline Canada & 20.7 & 92.9 & 27 \\
\hline France & 31.9 & 93 & 64 \\
\hline
\end{tabular}

Source: World Health Statistics, 2015, WHO.

Manpower unavailability is one of the important drawbacks of Indian healthcare system. According to the rural health care statistics 2015, the shortfall in health manpower in the 
post of female health worker (HW) / Auxiliary Nurse Midwife (ANM) is 5.21 percent of the total sanctioned post as per the minimum norms of one HW (F) /ANM per Sub Centre and Primary health Centre. The reason for the overall shortfall is the inter - state variation in the availability of female health worker. The states of Gujarat, Karnataka, Rajasthan, Tamil Nadu and Uttar Pradesh have the largest shortfall. Similarly, in the post of male health workers, the shortfall is 63.8 percent of the total post Out of the sanctioned posts, a large percentage of posts are vacant at the national and state levels in the country. For example, 10.5 per cent of the sanctioned posts of Female Health Worker HW (Female) /ANM are vacant against the 40.7 percent of the sanctioned posts of Male Health Worker HW (Male) as recorded in 2015. At the level of primary health care, there are $41.9 \%$ of Female Health Assistance/ LHV, $46.9 \%$ of Male Health Assistance and $27.0 \%$ of doctors sanctioned posts are vacant in the country as on 31 st march 2015. The efficiency of functioning of the sub - centers can be seen by the level of the existing manpower.5.3 per cent of the sub - centers are functioning without a HW (female) /
ANM and 46.5 percent are functioning without the HW (Male).3.3 percents are those sub - centers which are functioning without HW (female) /ANM as well as without a HW (male) as on 31st march 2015.

When we compared the female health worker availability in 2015 with that in 2005, it is observed that there is an increase in the number of ANMs at SCs and PHCs at the national level. The number of In Position ANMs increased from 133194 in 2005 to 212185 in 2015; an increase almost by $59.3 \%$. Looking at the picture of state level, it has been observed that only some states have shown increased number of ANMs at their SCs and PHCs in 2005 to 2015. The percentage of increase in the number of ANMs in the states of Assam is (0.61), Gujarat (0.07), Haryana (0.75), Karnataka (0.05), Kerala (0.43), Madhya Pradesh (0.33), Maharashtra 0.58), Odisha 0.22), Punjab 0.67), Uttar Pradesh (0.31), and West Bengal (1.06). Table 3.4; show a reduction in the number of ANMs in 2015 when compared with the figure in the year 2005. The reduction is observed in the states of Rajasthan, Tamil Nadu, and Andhra Pradesh.

Table 4: Health Worker [Female] / ANM at Sub Centers \& PHCs

\begin{tabular}{|c|c|c|c|c|c|c|c|c|c|c|}
\hline \multirow{3}{*}{ State } & \multicolumn{5}{|c|}{2005} & \multicolumn{5}{|c|}{2015} \\
\hline & \multicolumn{5}{|c|}{ Health Worker [Female]/ANM } & \multicolumn{5}{|c|}{ Health Worker [Female]/ANM } \\
\hline & Required & Sanction & In Position & Vacant & Shortfall & Required & Sanction & In Position & Vacant & Shortfall \\
\hline AP & 14092 & 14077 & 13740 & 337 & 352 & 8728 & 14111 & 11701 & 2410 & $*$ \\
\hline ASM & 5719 & 5719 & 5719 & 0 & 0 & 5635 & 5962 & 9220 & $*$ & $*$ \\
\hline $\mathrm{BR}$ & 11985 & NA & NA & NA & NA & 11612 & NA & 19499 & NA & $*$ \\
\hline GU & 8344 & 7274 & 6508 & 766 & 1836 & 9310 & 7274 & 6938 & 336 & 2372 \\
\hline HAR & 2841 & 2841 & 2818 & 23 & 23 & 3030 & 4810 & 4922 & $*$ & $*$ \\
\hline KAR & 9824 & 8756 & 8544 & 212 & 1280 & 11617 & 9264 & 8977 & 287 & 2640 \\
\hline KER & 6005 & 5675 & 5565 & 110 & 440 & 5402 & 7929 & 7950 & $*$ & $*$ \\
\hline MP & 10066 & 10027 & 9345 & 682 & 721 & 10363 & 10473 & 12412 & $*$ & $*$ \\
\hline MAH & 12233 & 11032 & 10699 & 333 & 1534 & 12391 & 18636 & 16922 & 1714 & $*$ \\
\hline ORS & 7209 & 7121 & 6768 & 353 & 441 & 7993 & NA & 8245 & NA & $*$ \\
\hline PUN & 3342 & 2704 & 2602 & 102 & 740 & 3378 & 4675 & 4347 & 328 & $*$ \\
\hline RAJ & 12225 & 11425 & 11425 & 0 & 800 & 16490 & 21704 & 15999 & 5705 & 491 \\
\hline $\mathrm{TN}$ & 10062 & 10366 & 10112 & 254 & $*$ & 10078 & 9993 & 8477 & 1516 & 1601 \\
\hline UP & 24181 & 18577 & 18146 & 431 & 6035 & 24018 & 27334 & 23731 & 3603 & 287 \\
\hline WB & 11529 & 10356 & 9070 & 1286 & 2459 & 11266 & 20500 & 18723 & 1777 & $*$ \\
\hline IND & 169262 & 139798 & 133194 & 6640 & 19311 & 178963 & 195672 & 212185 & 20492 & 9326 \\
\hline
\end{tabular}

Source: Rural Health Statistics, Ministry of Health and Family Welfare, Govt of India.

Community Health Centres (CHCs) provide highly specialized health care accommodated with highly qualified doctors and medical professionals such as surgeons, obstetricians and gynecologists, physicians and pediatricians. The current position of total specialist's health care personnel at CHCs in 2015 is shown in table.5. Table shows that there is continuous decline in the number of total health specialist from the 2005 - 2015. In U. P the number of specialists available in the year of 2012 is very satisfactory. But after this there are massive decline in the numbers and it is only 448 in the 2015 . The low number of available health care personnels negatively affects the availability of facilities for the utilization of the people. In this scenario the cost to avail health services increases as the availability of health services is lesser in the quantity of its demands.

Table 5: Total Health Specialists at CHCs in India and States

\begin{tabular}{|c|c|c|c|c|c|c|c|c|c|c|c|}
\hline States & 2005 & 2006 & 2007 & 2008 & 2009 & 2010 & 2011 & 2012 & 2013 & 2014 & 2015 \\
\hline AP & 224 & 224 & 166 & 235 & 480 & 480 & 408 & 346 & 275 & 275 & 159 \\
\hline ASM & 200 & NA & NA & 365 & 142 & 209 & 216 & 122 & 119 & 121 & NA \\
\hline BR & NA & NA & 104 & 104 & 104 & 104 & 151 & 151 & 98 & 69 & 63 \\
\hline GUJ & 122 & 92 & 82 & 81 & 76 & 79 & 76 & 76 & 74 & 74 & 74 \\
\hline AR & 45 & 49 & 39 & 45 & 79 & 70 & 45 & 29 & 26 & 29 & 30 \\
\hline KAR & 694 & 691 & 691 & 691 & 691 & 726 & 584 & 495 & 495 & 495 & 502 \\
\hline KER & 114 & 82 & 115 & 115 & 794 & 774 & 774 & 774 & 33 & 39 & 39 \\
\hline MP & NA & 49 & 503 & 220 & 245 & 245 & 227 & 267 & 263 & 263 & 263 \\
\hline MAH & 1099 & 1099 & 448 & 352 & 438 & 954 & 600 & 514 & 489 & 462 & 356 \\
\hline ORS & NA & NA & NA & NA & 371 & 469 & 438 & 317 & 305 & 346 & 356 \\
\hline
\end{tabular}




\begin{tabular}{|c|c|c|c|c|c|c|c|c|c|c|c|}
\hline PUJ & 315 & 226 & 117 & 210 & 254 & 300 & 300 & 279 & 255 & 202 & 173 \\
\hline RAJ & 586 & 581 & 600 & 651 & 598 & 492 & 569 & 148 & 148 & 651 & 526 \\
\hline TN & 48 & 48 & 725 & NA & 0 & 0 & 0 & 0 & 0 & 0 & 0 \\
\hline UP & NA & NA & $\mathbf{4 1 3}$ & $\mathbf{6 1 8}$ & $\mathbf{6 1 8}$ & $\mathbf{6 1 8}$ & $\mathbf{1 2 5 6}$ & $\mathbf{1 8 9 4}$ & $\mathbf{1 7 4 0}$ & $\mathbf{4 8 4}$ & $\mathbf{4 4 8}$ \\
\hline WB & 133 & 133 & 624 & 186 & 175 & 175 & 175 & 175 & 1062 & 115 & 114 \\
\hline INDIA & $\mathbf{3 9 5 3}$ & $\mathbf{3 5 5 0}$ & $\mathbf{5 1 1 7}$ & $\mathbf{4 2 7 9}$ & $\mathbf{5 7 8 9}$ & $\mathbf{6 7 8 1}$ & $\mathbf{6 9 3 5}$ & $\mathbf{5 8 5 8}$ & $\mathbf{5 8 0 5}$ & $\mathbf{4 0 9 1}$ & $\mathbf{4 0 7 8}$ \\
\hline
\end{tabular}

Source: Rural Health Statistics, 2005, 2012, 2015, Government of India.

The shortfall of total specialists is comparatively high in most of the states. In 2015, the highest shortfall of total specialists is recorded in the states of Kerala, out of the total 888 required total specialists only 39 are in position and state experiences a shortfall of 849 total specialist's posts at CHCs. The percentage shortfall of total specialists in Kerala is 95.6, followed by Gujarat with a shortfall of 94.2 percent in the required total specialists at the CHCs, other states like Haryana has a shortfall of 93.1 percent, West Bengal has 91.8 percent. The lowest shortfall is recorded in the states of Karnataka with 39.1 percent and Maharashtra with 59.9 percent of the shortfall in the required total specialist's posts at CHCs in 2015 (Table 3.5).

On comparing with the manpower in position in 2015 with that in 2005 , as presented in the table 3.5 , it was seen that in 2015 , the total specialists in position has increased as against that in 2005. Out of the sanctioned posts, a large percentage of posts are vacant at the national and state levels in the country. For example, 10.5 per cent of the sanctioned posts of Female Health Worker HW (Female) / ANM are vacant against the 40.7 percent of the sanctioned posts of Male Health Worker HW (Male) as recorded in 2015. At the level of primary health care, there are $41.9 \%$ of Female Health Assistance/ LHV, $46.9 \%$ of Male Health Assistance and $27.0 \%$ of doctors sanctioned posts are vacant in the country as on 31st march 2015. The efficiency of functioning of the sub - centers can be seen by the level of the existing manpower.5.3 per cent of the sub - centers are functioning without a HW (female) / ANM and 46.5 percent are functioning without the HW (Male).3.3 percents are those sub - centers which are functioning without HW (female) / ANM as well as without a HW (male) as on 31st march 2015.

In the table. 6 the number of surgeons required as well as sanctioned and in position has been showed for the year 2015. In this table we can see that in the state of Uttar Pradesh, total 773 surgeons were required for the provision of quality health service. Out of them only 529 post of surgeons were sanctioned by the government. Among the sanctioned positions only 112 surgeons were started working in the rural areas of the state. It means there is a total shortfall of 661 surgeons in a year from the required number. Total 47 posts were still vacant. This table shows that the less quantity of required surgeons forces inhabitants of rural areas to make their way toward the private hospital for the caesarian purpose. The primary survey of study area shows that the allotted surgeons came only one day in a week to the $\mathrm{CHCs}$ and rest of days of the weeks surgeries were performed by other unskilled staff of the hospitals.
Table 6: Number of Surgeons Required, Sanctioned and in Position in Year 2015

\begin{tabular}{|c|c|c|c|c|c|}
\hline \multicolumn{7}{|c|}{ SURGEONS at CHCs } \\
\hline \multirow{2}{*}{ State } & Required & Sanctioned & In Position & Vacant & Shortfall \\
\cline { 2 - 6 } & R & S & P & S - P & R - P \\
\hline AP & 179 & 96 & 19 & 77 & 160 \\
\hline ASM & 151 & NA & 24 & NA & 127 \\
\hline BR & 70 & NA & 21 & NA & 49 \\
\hline GUJ & 320 & 278 & 32 & 246 & 288 \\
\hline HAR & 109 & 40 & 6 & 34 & 103 \\
\hline KAR & 206 & 206 & 128 & 78 & 78 \\
\hline KER & 222 & 0 & 0 & 0 & 222 \\
\hline MP & 334 & 239 & 51 & 188 & 283 \\
\hline MAH & 360 & 202 & 90 & 112 & 270 \\
\hline ORS & 377 & 133 & 81 & 52 & 296 \\
\hline PUN & 150 & 145 & 43 & 102 & 107 \\
\hline RAJ & 568 & 505 & 163 & 342 & 405 \\
\hline TN & 385 & 0 & 0 & 0 & 385 \\
\hline UP & $\mathbf{7 7 3}$ & $\mathbf{5 2 9}$ & $\mathbf{1 1 2}$ & $\mathbf{4 1 7}$ & $\mathbf{6 6 1}$ \\
\hline WB & 347 & 549 & 3 & 546 & 344 \\
\hline IND & $\mathbf{5 3 9 6}$ & $\mathbf{3 3 2 0}$ & $\mathbf{8 9 6}$ & $\mathbf{2 4 7 7}$ & $\mathbf{4 5 0 0}$ \\
\hline
\end{tabular}

Source: Rural Health Statistics, Ministry of Health and Family Welfare, Govt. of India.

In the table.7 the number of obstetrician and gynecologist has been described. It can be seen from the table that in the state of Uttar Pradesh the required number of Obstetrician and Gynecologist was 773 out of which only 524 posts were sanctioned by the government. Among this only 115 were presently working in the rural areas of the state. The total shortfall of 658 doctors was recognized. In this 409 post were still vacant. This picture shows that there are wide gap between the available doctors and patients' ratio. These negative ratios of doctor patients adversely affect the provision of quality health care and making a more viable path for the emergence of private sector in the health industry. This further affects the patients as more out of pocket expenditure has been done in order to avail better health care facility.

Table 3.7: Number of Obstetricians and Gynecologists at the CHCs

\begin{tabular}{|c|c|c|c|c|c|}
\hline \multicolumn{7}{|c|}{ (As on 31st March, 2015) } \\
\hline \multirow{2}{*}{ tate } & Required & Sanctioned & In Position & Vacant & Shortfall \\
\cline { 2 - 6 } & R & S & P & S - P & R - P \\
\hline AP & 179 & 96 & 55 & 41 & 124 \\
\hline ASM & 151 & NA & 69 & NA & 82 \\
\hline BR & 70 & NA & 16 & NA & 54 \\
\hline GUJ & 320 & 33 & 31 & 2 & 289 \\
\hline HAR & 109 & 31 & 6 & 25 & 103 \\
\hline KAR & 206 & 206 & 173 & 33 & 33 \\
\hline KER & 222 & 14 & 20 & NA & 202 \\
\hline MP & 334 & 297 & 55 & 242 & 279 \\
\hline MAH & 360 & 244 & 217 & 27 & 143 \\
\hline ORS & 377 & 380 & 145 & 235 & 232 \\
\hline PU & 150 & 145 & 70 & 75 & 80 \\
\hline
\end{tabular}




\begin{tabular}{|c|c|c|c|c|c|}
\hline RAJ & 568 & 271 & 99 & 172 & 469 \\
\hline TN & 385 & 0 & 0 & 0 & 385 \\
\hline UP & $\mathbf{7 7 3}$ & $\mathbf{5 2 4}$ & $\mathbf{1 1 5}$ & $\mathbf{4 0 9}$ & $\mathbf{6 5 8}$ \\
\hline WB & 347 & 787 & 41 & 746 & 306 \\
\hline IND & $\mathbf{5 3 9 6}$ & $\mathbf{3 4 2 9}$ & $\mathbf{1 2 9 6}$ & $\mathbf{2 2 4 2}$ & $\mathbf{4 1 1 5}$ \\
\hline
\end{tabular}

Source: Rural Health Statistics, Ministry of Health and Family Welfare, Govt. of India.

In the table. 8 the required, sanctioned and in position number of general physicians has been depicted. In the state of Uttar Pradesh total 773 physicians were required at the CHCs state.

Table 3.8: Number of Physicians at the CHCs

\begin{tabular}{|c|c|c|c|c|c|}
\hline \multicolumn{7}{|c|}{ Physicians at CHCs } \\
\hline \multirow{2}{*}{ State } & Required & Sanctioned & In Position & Vacant & Shortfall \\
\cline { 2 - 6 } & $\mathrm{R}$ & $\mathrm{S}$ & $\mathrm{P}$ & $\mathrm{S}-\mathrm{P}$ & $\mathrm{R}-\mathrm{P}$ \\
\hline AP & 179 & 96 & 38 & 58 & 114 \\
\hline ASM & 151 & NA & 9 & NA & 142 \\
\hline BR & 70 & NA & 13 & NA & 57 \\
\hline GUJ & 320 & NA & 9 & NA & 311 \\
\hline HAR & 109 & 48 & 11 & 37 & 98 \\
\hline KAR & 206 & 206 & 102 & 104 & 104 \\
\hline KER & 222 & 2 & 2 & 0 & 220 \\
\hline MP & 334 & 196 & 72 & 124 & 262 \\
\hline MAH & 360 & 153 & 88 & 65 & 323 \\
\hline ORS & 377 & 133 & 54 & 79 & 323 \\
\hline PU & 150 & 130 & 28 & 102 & 122 \\
\hline RAJ & 568 & 561 & 175 & 386 & 393 \\
\hline TN & 385 & 0 & 0 & 0 & 385 \\
\hline UP & $\mathbf{7 7 3}$ & $\mathbf{5 2 3}$ & $\mathbf{1 0 3}$ & $\mathbf{4 2 0}$ & $\mathbf{6 7 0}$ \\
\hline WB & 347 & 277 & 51 & 226 & 296 \\
\hline IND & $\mathbf{5 3 9 6}$ & $\mathbf{2 7 7 2}$ & $\mathbf{9 1 8}$ & $\mathbf{1 8 8 9}$ & $\mathbf{4 4 7 9}$ \\
\hline
\end{tabular}

Source: Rural Health Statistics, Ministry of Health and Family Welfare, Govt. of India.

Among them only 523 posts were sanctioned. Out of which only 103 physicians were appointedat the CHCs. Total 420 posts were still vacant and 670 physicians shortfall has been noticed. When we compare this data with the overall physicians appointed in the all states the demand were of 5396 while only 2772 were sanctioned out of which only 918 physicians were appointed. Total 4479 physicians' shortfall has been calculated from the required number.

In the table 3.9 the number of Pharmacist at the PHCs and $\mathrm{CHCs}$ has been calculated. In UP the total number of pharmacist at the health centres have been calculated as 4270 required. Out of the total required numbers only 2952 have been sanctioned. In which 2883 were recruited in the rural areas. Total 1387 pharmacists shortfall has been seen. The unavailability of recruited pharmacist at the PHCs and $\mathrm{CHCs}$ are another problem which are kept unquestioned.

The low numbers of health care personnals in the rural areas create havoc to the provision of qualitative health care by the government. Both in the country in comparison to other SAARC countries and at the level of state UP were the most underperforming state in the health sector. This condition also prevails when we compare these data with the data of district level. The district of Allahabad has been chosen as the study area. Here population per bed at a $\mathrm{CHC}$ has been computed. With this per doctor population, spatial coverage of per CHCs has been calculate to know the condition of health care facility in the Allahabad.

Table 9: Number of Pharmacists at the PHCs and CHCs PHARMACISTS at PHCs \& CHCs (As on 31st March, 2015)

\begin{tabular}{|c|c|c|c|c|c|}
\hline \multicolumn{7}{|c|}{ PHARMACISTS at PHCs \& CHCs } \\
\hline \multirow{2}{*}{ State } & Required & Sanctioned & In Position & Vacant & Shortfall \\
\cline { 2 - 6 } & R & S & P & S - P & R - P \\
\hline AP & 1248 & 1279 & 951 & 328 & 297 \\
\hline ASM & 1165 & 1284 & 1347 & $*$ & $*$ \\
\hline BR & 1953 & 989 & 250 & 739 & 1703 \\
\hline GUJ & 1567 & 1550 & 879 & 671 & 688 \\
\hline HAR & 570 & 568 & 508 & 60 & 62 \\
\hline KAR & 2559 & 2668 & 2521 & 147 & 38 \\
\hline KER & 1049 & 1036 & 1102 & $*$ & $*$ \\
\hline MP & 1505 & 1443 & 1023 & 420 & 482 \\
\hline MAH & 2171 & 2355 & 2100 & 255 & 71 \\
\hline ORS & 1682 & 1819 & 1499 & 320 & 183 \\
\hline PU & 577 & 841 & 806 & 35 & $*$ \\
\hline RAJ & 2651 & 1282 & 667 & 615 & 1984 \\
\hline TN & 1757 & 1799 & 1526 & 273 & 231 \\
\hline UP & $\mathbf{4 2 7 0}$ & $\mathbf{2 9 5 2}$ & $\mathbf{2 8 8 3}$ & $\mathbf{6 9}$ & $\mathbf{1 3 8 7}$ \\
\hline WB & 1256 & 1229 & 966 & 263 & 290 \\
\hline IND & $\mathbf{3 0 7 0 4}$ & $\mathbf{2 8 2 6 8}$ & $\mathbf{2 3 1 3 1}$ & $\mathbf{5 4 5 6}$ & $\mathbf{8 3 2 1}$ \\
\hline
\end{tabular}

Source: Rural Health Statistics, Ministry of Health and Family Welfare, Govt. of India.

In the table 3.9 the number of Pharmacist at the PHCs and CHCs has been calculated. In UP the total number of pharmacist at the health centres have been calculated as 4270 required. Out of the total required numbers only 2952 have been sanctioned. In which 2883 were recruited in the rural areas. Total 1387pharmacists shortfall has been seen. The unavailability of recruited pharmacist at the PHCs and $\mathrm{CHCs}$ are another problem which are kept unquestioned.

The low numbers of health care personals in the rural areas create havoc to the provision of qualitative health care by the government. Both in the country in comparison to other SAARC countries and at the level of state UP were the most underperforming state in the health sector. This condition also prevails when we compare these data with the data of district level. Here population per bed at a CHC, per doctor population, spatial coverage of per $\mathrm{CHCs}$ has been an important indicator to know the condition of health care facility at the district level. The above mentioned factors and data shows regular fall in the number as well as in the quality of the health care facilities.

\section{References}

[1] Abel - Smith, B. and A. Leiserson (1978), "Poverty, Development and Health Policy", Public Health Papers, (69), World Health Organisation, Geneva.

[2] Abel - Smith, B. (1980), "Economics and Health Policy An Overview", in A. Griffths and Bankowski (ed). Economics and Health Policy, Published by Council for International Organisations of Medical Sciences and The Sandoz Institute of Health and Socio - Economic Studies, Geneva.

[3] Akhtar, R. (1978), "Spatial Distribution and Growth of Health Facil - ities in Rajasthan", Geographical Review of India, Vol.40, No.3. 
[4] Bailey, W. and D. R. Phillips (1990), "Spatial Patterns of Use of Health Services in The Kingston Metropolitan Area, Jamica", Social Science and Medicine, Vol.30, No.1, pp.1 - 12.

[5] Banerji, D. (1971), Family Planning In India: A Critiaue and a Perspective, People's Publishing

[6] Ghosh, B. N. and A. B. Mukherjee (1989), "An Analysis of Health Services Coverage of a Primary Health Centre of a Primary Health Centre in West Bengal", Indian_Journal of Public Health, Vol. XXXIII, No.1.

[7] Giggs, J. A. (1979), "Human Health Problems in Urban Areas", in David T. Herbert and D. M. Smith (ed.), Social P oblems and the City Geographical Perspective, Oxford University Press, New York, pp.84 - 106.

[8] Joyce, J. (1961), Health in New India India's War Against Disease Foundation, Delhi. The Storv of (1947 - 1961), The Free Ford

[9] Jeffery, R. (1976), "Health Care Delivery System", Economic and Political Weekly, Vol. XI, No.28, pp.1046 - 47.

[10] Jehlik, P. J. and Distance Personnel Illness", R. L. McNarrnara (1952), "The Relation of to Differential use of Certain Health and Facilities and the Extent of Bed Rural Sociology, Vol.17, pp.261 - 265. 